\title{
Using the Model Statement Technique as a Lie Detection Tool: A Cross-Cultural Comparison
}

\author{
Aldert Vrij ${ }^{*}$, Sharon Leal ${ }^{\mathrm{a}}$, Samantha Mann ${ }^{\mathrm{a}}$, Alla Shaboltas ${ }^{\mathrm{b}}$, \\ Maria Khaleeva ${ }^{\mathrm{b}}$, Juliana Granskaya ${ }^{\mathrm{b}}$, Eunkyung Jo ${ }^{\mathrm{c}}$ \\ a Department of Psychology, University of Portsmouth, Portsmouth, United Kingdom \\ b Department of Psychology, St. Petersburg State University, St. Petersburg, Russia \\ c Department of Psychology, Dongguk University, Seoul, Republic of Korea \\ *Corresponding author. E-mail: aldert.vrij@port.ac.uk
}

Background. Researchers have started to demonstrate that verbal cues to deceit can be elicited through specific interview protocols. One that has yielded success is the Model Statement technique, which works as a social comparison and raises interviewees' expectations about how much information they are required to report. This technique has been developed and tested in the United Kingdom, and is used in the field. A tool used in the field should be thoroughly examined in different settings, including in different cultures.

Objective. We examined the effect of the Model Statement tool on eliciting information and cues to deceit in Russian and South Korean participants.

Design. A total of 160 Russian and South Korean participants were recruited via an advert on the university intranets and advertisement leaflets. The advert explained that the experiment would require participants to tell the truth or lie about a trip away that they may (or may not) have taken within the last year. Truth tellers described a trip they made during the last twelve months, whereas liars made up a story about such a trip. Half of the participants listened to a Model Statement at the beginning of the interview. The dependent variables were "detail", "complications", "common knowledge details", "self-handicapping strategies", and "ratio of complications".

Results. The Model Statement elicited more details from both Russian and South Korean participants and strengthened "complications" and "ratio of complications" as cues to deceit in both samples. The effects were the strongest amongst South Korean participants.

Conclusion. The Model Statement technique seems to work across different cultures, but more research is required to determine why it worked better amongst South Korean than Russian participants.
Keywords:

Model Statement, cross-cultural comparison, information gathering, deception 


\section{Introduction}

Research spanning several decades has shown that cues to the deceit that liars spontaneously display are faint and unreliable (DePaulo et al., 2003). Consequently, researchers have started to examine whether such cues can be elicited through specific interview protocols (Vrij \& Granhag, 2012). One technique that has yielded success is the Model Statement technique, which is now used in the field (Vrij, Leal, \& Fisher, 2018). It has been developed in the United Kingdom and tested on British participants (Leal, Vrij, Warmelink, Vernham, \& Fisher, 2015; Vrij, Leal, Jupe, \& Harvey, 2018). A tool that is used in the field should be thoroughly examined in different settings, including in different cultures. In this study, we examined the efficacy of the Model Statement with Russian and South Korean participants.

A Model Statement is a detailed example of an account unrelated to the topic of investigation (Leal et al., 2015). It works as a social comparison and raises interviewees' expectations about how much information is required from them in an answer. Raising such expectations is often needed because interviewees tend to underestimate how much detail they are supposed to report (Vrij, Hope, \& Fisher, 2014). A Model Statement works better to elicit as many details as possible than a verbal instruction to report all details someone can remember, because the Model Statement is an example of a detailed answer, and examples are usually easier to follow than instructions (Vrij, Leal, \& Fisher, 2018).

Since a Model Statement raises expectations amongst both truth tellers and liars that they should provide more details, both groups tended to report a similar amount of additional details after being exposed to a Model Statement (see Vrij, Leal, and Fisher [2018] for a review of Model Statement deception research). However, truth tellers and liars appear to provide different details after listening to a Model Statement, with truth tellers reporting more complications than liars, and obtaining a higher ratio of complications score than liars (Vrij, Leal, \& Fisher, 2018). A complication (e.g., "Initially we did not see our friend, as he was waiting at a different entrance") is an occurrence that makes a situation more difficult to report than necessary (Vrij, Leal, \& Fisher, 2018). In interviews, liars prefer to keep their stories simple (Hartwig, Granhag, \& Strömwall, 2007), but adding complications makes the story more complex. A Model Statement increases the number of complications interviewees report, particularly for truth tellers (Vrij et al., 2017; Vrij, Leal, Jupe, \& Harvey, 2018). Complications are often not about key aspects of the activities that someone describes, and the story can be well understood without reporting the complications. Therefore, truth tellers may leave at least some of them out when they have not been exposed to a Model Statement. Liars are reluctant to provide complications, in order to keep their story simple.

To examine the ratio of complications, two verbal cues need to be considered which are thought to be more present in liars' than in truth tellers' accounts: "common knowledge details" and "self-handicapping strategies". Common knowledge details refer to strongly invoked stereotypical information about events ("We visited the Louvre museum where we saw the Mona Lisa") (Vrij et al., 2017). Liars are more likely to include common knowledge details in their statements than truth tellers (Sporer, 2016). Truth tellers have personal experiences of an event and are likely to report such unique experiences. When they do 
so, the statement goes beyond reporting stereotypical information. If liars do not have personal experiences of the event they report, they will draw upon general knowledge to construe the event. Even if liars do have personal experiences of such an event, they may not report them due to their desire to keep their stories simple. "Self-handicapping strategies" refer to justifications as to why someone is not able to provide information ("I can't remember; it was a while ago when this happened") (Vrij et al., 2017). Liars are more likely to include self-handicapping strategies in their statements than truth tellers (Vrij et al., 2017). For liars, who are inclined to keep their stories simple, not having to provide information is an attractive strategy. However, liars are also concerned about their credibility and believe that admitting lack of knowledge and/or memory appears suspicious (Ruby \& Brigham, 1998). A potential solution is to provide a justification for the inability to provide information.

The ratio of complications (complications / [complications + common knowledge details + self-handicapping strategies]) should be a more diagnostic cue to deceit than the cue "total details", because it takes the different strategies from truth tellers and liars better into account. Research has shown that truth tellers typically report more details than do liars (Amado, Arce, Fariña, \& Vilarino, 2016), because liars are unable or unwilling to provide as much information as truth tellers do (Vrij, 2008). They may be unable because they lack the imagination to report as many plausible details as truth tellers do or they may be unwilling out of fear that such details would give their lies away. However, the combined measure "total details" includes details that are more likely to be reported by truth tellers (complications) and details that are more likely to be reported by liars (common knowledge details and self-handicapping strategies). The ratio of complications score makes apparent the different verbal cues truth tellers and liars use - it should be higher in truth tellers, and should therefore be a more diagnostic cue to deceit than the generic measure "total details".

Different communication styles are used in different cultures. A communication style is the way people communicate with others (Liu, 2016). A frequently used distinction is that between high-context and low-context communication (Hall, 1976). According to Hall (1976), messages exchanged in high-context cultures (e.g., South Korea) carry implicit meanings and rely heavily on context. In a higher-context culture, many things are left unsaid, letting the culture explain. Words become important in higher-context communication, since a few words can communicate a complex message very effectively to an in-group member. By contrast, in low-context cultures (e.g., Russia), it is important for the communicator to be explicit in order to be fully understood. This would imply that interviewees in low-context cultures would provide more information to make the message understood. There is no theoretical reason to predict that a Model Statement would work in one culture but not in another; however, a Model Statement may be more effective in high-context cultures than in low context-cultures. A Model Statement has more potential to elicit additional information and cues to deceit if an interviewee volunteers less information without having listened to a Model Statement (Model Statement-present condition), which we expect to happen in high-context cultures. 


\section{Hypotheses}

We formulated the following hypotheses:

- Truth tellers will report more details than liars (Hypothesis 1).

- Truth tellers will include in their statements more complications (Hypothesis 2a), fewer common knowledge details (Hypothesis $2 b$ ), and fewer selfhandicapping strategies (Hypothesis 2c) than liars.

- Truth tellers will obtain a higher ratio of complications than liars and this cue will be a more diagnostic cue to deceit than total details (Hypothesis 3).

- A Model Statement will increase the number of reported details both in truth tellers and liars (Hypothesis 4).

- A Model Statement will increase the number of complications, particularly amongst truth tellers (Hypothesis 5).

- Following on from Hypothesis 5, the ratio of complications will be higher in truth tellers than in liars, particularly in the Model Statement-present condition (Hypothesis 6).

- South Korean participants (high-context culture) are expected to provide fewer details than Russian participants (low-context culture) (Hypothesis 7).

- The Model Statement effects presented in Hypotheses 4 to 6 should work in both Russian and South Korean participants, but particularly in South Korean participants (Hypothesis 8).

To test the hypotheses, we used part of a data set previously reported in Vrij et al. (2017). We used the Korean and Russian participants and left out the Hispanic participants, because that sample was too small $(n=39)$ for reliable analysis. In Vrij et al. (2017) the same dependent variables were reported as in the present article; however, in the earlier article, the data were not analysed for the Korean and Russian participants separately. Instead, the focus was on the effect of the presence of an interpreter on the dependent variables. In the present analyses, we were not interested in the effect of an interpreter, and included that factor as a covariate in the hypotheses-testing analyses.

\section{Method}

\section{Participants}

A total of 160 participants (34 males, 125 females, and two unknown) took part in the study. Their age ranged from 18 to 38 years with an average age of $M=21.67$ years $(S D=2.67)$. Participation took place in universities in the Republic of South Korea and the Russian Federation and the nationality of the participants was South Korean $(n=80)$ and Russian $(n=80)$.

\section{Procedure Outline}

We present here an outline of the procedure (see Vrij et al. [2017] for a full description). Truth tellers $(n=76)$ discussed a trip they had made during the last twelve months, whereas liars $(n=84)$ pretended to have made such a trip. Both truth tellers and liars were given time to prepare themselves for the interview, which 
consisted of six questions about the planning of the trip and experiences during the trip. In the Model Statement-present $(n=80)$ condition, participants listened at the beginning of the interview to a detailed audiotaped account in which someone described attending a motor racing event presented in the interviewee's native language (Leal et al., 2015). In a pre-interview questionnaire, participants were asked about their motivation to perform well during the interview, with (5) indicating high motivation. They were also asked about the thoroughness of their preparation ([7] indicated high thoroughness) and the preparation time given ([7] indicated sufficient).

\section{Coding}

The interviews were transcribed and translated into English. The coding was done by English coders based on the English transcripts. All coders were blind to the hypotheses and Veracity status of the interviewee. One coder coded each detail in the interview. To give an example, the answer "We went to the beach until 7 o'clock. We swam, ate sandwiches, and drank beer" contained six details. A second coder coded a random sample of 50 transcripts. Inter-rater reliability between the two coders, using the two-way random effects model for measuring consistency, was high (Single Measures ICC $=.87$ ).

Two coders coded independently from each other complications, common knowledge details, and self-handicapping strategies. Examples are: "Generally, we were about to miss the performance because of me, because they have another time there, an hour gain or lose, something like that" (complication); "We drank a lot during the flight and when the guys met us we continued to drink walking in the city" (common knowledge detail) and "I did not organise anything, our trips are always planned by dad" (self-handicapping strategy). Inter-rater reliability between the two coders was high for complications (Average Measures, Intraclass correlation coefficient, ICC $=.95$ ) and self-handicapping strategies (Average Measures ICC $=.85$ ) and satisfactory for common knowledge details (Average Measures ICC $=.64)$. Disagreements were resolved between the two coders. The ratio of complications was calculated as complications / (complications + common knowledge details + self-handicapping strategies).

\section{Results}

\section{Preparation Thoroughness, Preparation Time, Motivation, and How Many Days Discussed}

Four ANOVAs with Veracity and Nationality as factors and preparation thoroughness, preparation time, motivation, and how many days away discussed during the interview as dependent variables revealed one main effect for Veracity (preparation time: $F(1,156)=27.43, p<.001, d=0.81,95 \% \mathrm{CI}[0.48,1,12)])$ and two main effects for Nationality (preparation time: $F(1,156)=13.16, p<.001, d=0.56 .95 \% \mathrm{CI}$ $[0.24,0.87]$ and for how many days discussed: $F(1,156)=8.89, p=.003, d=0.48$, $95 \%$ CI $[0.16,0.79])$.

Truth tellers $(M=6.13, S D=1.21,95 \% C I[5.79,6.46])$ rated their preparation time as more sufficient than did liars $(M=4.89, S D=1.76,95 \% \mathrm{CI}[4.59,5.22])$. In 
addition, Russians $(M=5.93, S D=1.37,95 \% C I[5.61,6.26])$ rated their preparation time as more sufficient than did South Koreans $(M=5.04, S D=1.78,95 \%$ CI $[4.77,5.42])$. Russians $(M=5.16, S D=5.42,95 \% C I[4.18,6.10])$ also discussed more days than did South Koreans $(M=3.05, S D=2.97,95 \%$ CI $[2.13,4.05])$. We included preparation time and how many days discussed as covariates in the hypotheses testing analyses, together with the Interpreter factor.

\section{Hypothesis Testing}

We carried out MANCOVAs to test the hypotheses. We also examined Bayes Factors $(\mathrm{BF})$ analyses, which is a method to test the probability of the observed data under the null hypothesis compared to the alternative hypothesis (Wetzels \& Wagenmakers, 2012). $\mathrm{A} \mathrm{BF}_{10}$ smaller than 1 indicates evidence for the absence of an effect (support of the null hypothesis), BFs between 1 and 3 suggest weak evidence, and BFs between 3 and 10 suggest substantial evidence (Jeffreys, 1961). We used the default Cauchy's prior of .707 for the Bayesian $t$-tests (Lakens, 2016).

A 2 (Veracity) $\times 2$ (Model Statement) $\times 2$ (Nationality) MANCOVA was conducted with detail, complications, common knowledge details, self-handicapping strategies, and ratio of complications as dependent variables, and preparation time, number of days discussed during the interview, and interpreter as covariates.

At a multivariate level, significant main effects emerged for Veracity, $F(5$, $145)=10.92, p<.001, \eta_{\mathrm{p}}{ }^{2}=.27$, Model Statement, $F(5,145)=3.69, p=.004$, $\eta_{\mathrm{p}}{ }^{2}=.11$, and Nationality, $F(5,145)=3.82, p=.003, \eta_{\mathrm{p}}{ }^{2}=.12$. The Veracity $\times$ Model Statement effect was also significant, $F(5,145)=3.50, p=.005, \eta_{\mathrm{p}}{ }^{2}=.11$.

At a univariate level, one Nationality effect emerged: South Koreans $(M=3.78$, $S D=2.16,95 \%$ CI $[3.23,4.13])$ included more common knowledge details in their reports than did Russians, $(M=2.44, S D=2.21,95 \%$ CI $[1.98,2.90]), F(1$, $149)=13.65, p<.001, d=0.61,95 \% \mathrm{CI}[0.29,0.92]$. Relevant for testing Hypothesis 7 is the finding that the Russians and South Koreans reported a similar amount of detail, $F(1,149) 0.91, p=.343, d=.16,95 \% \mathrm{CI}[0.15,0.45], \mathrm{BF}_{10}=.27$. This means that Hypothesis 7 is rejected. Perhaps a better test for Hypothesis 7 is to examine Nationality differences in the Model Statement-absent condition only. Even in that condition, Russian and South Korean participants provided a similar amount of detail, $F(1,73)=0.13, p=.719, d=.00,95 \% \mathrm{CI}[-0.44,0.44], \mathrm{BF}_{10}=.23$.

Since the Veracity $\times$ Model Statement interaction effect is more informative than the Veracity and Model Statement main effects, only the interaction effect will be discussed. We hereby discuss these interaction effect findings for the two nationalities separately, as this cross-cultural comparison was the aim of this article.

\section{Russian Participants}

A 2 (Veracity) $\times 2$ (Model Statement) MANCOVA was conducted on the Russian sample with detail, complications, common knowledge details, self-handicapping strategies, and ratio of complications as dependent variables, and preparation time, number of days discussed during the interview, and interpreter as covariates. At a multivariate level, a significant main effect emerged for Veracity, $F(5,69)=4.53$, $p=.001, \eta_{\mathrm{p}}{ }^{2}=.25$, whereas the Model Statement main effect, $F(5,69)=0.96$, 


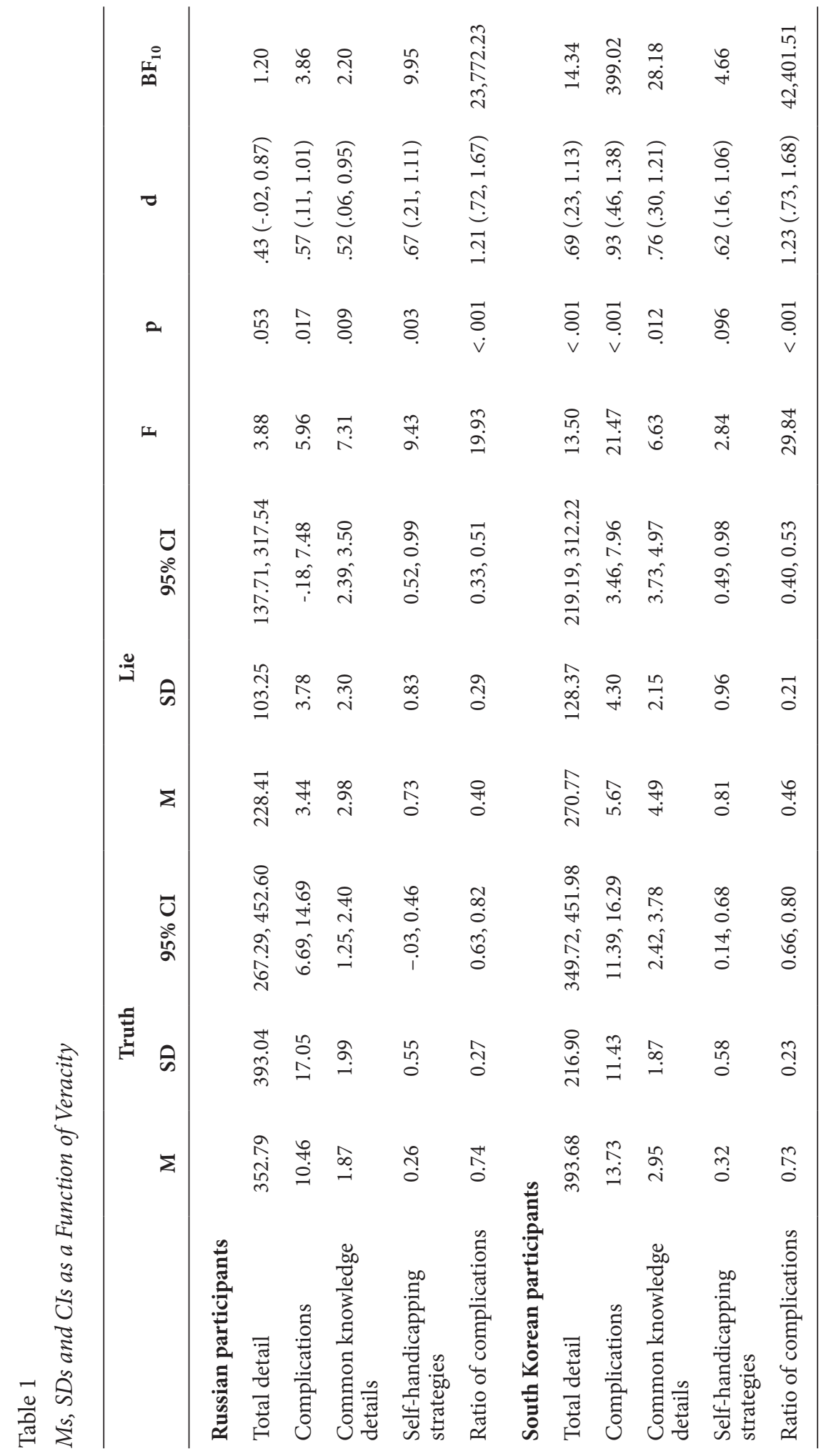




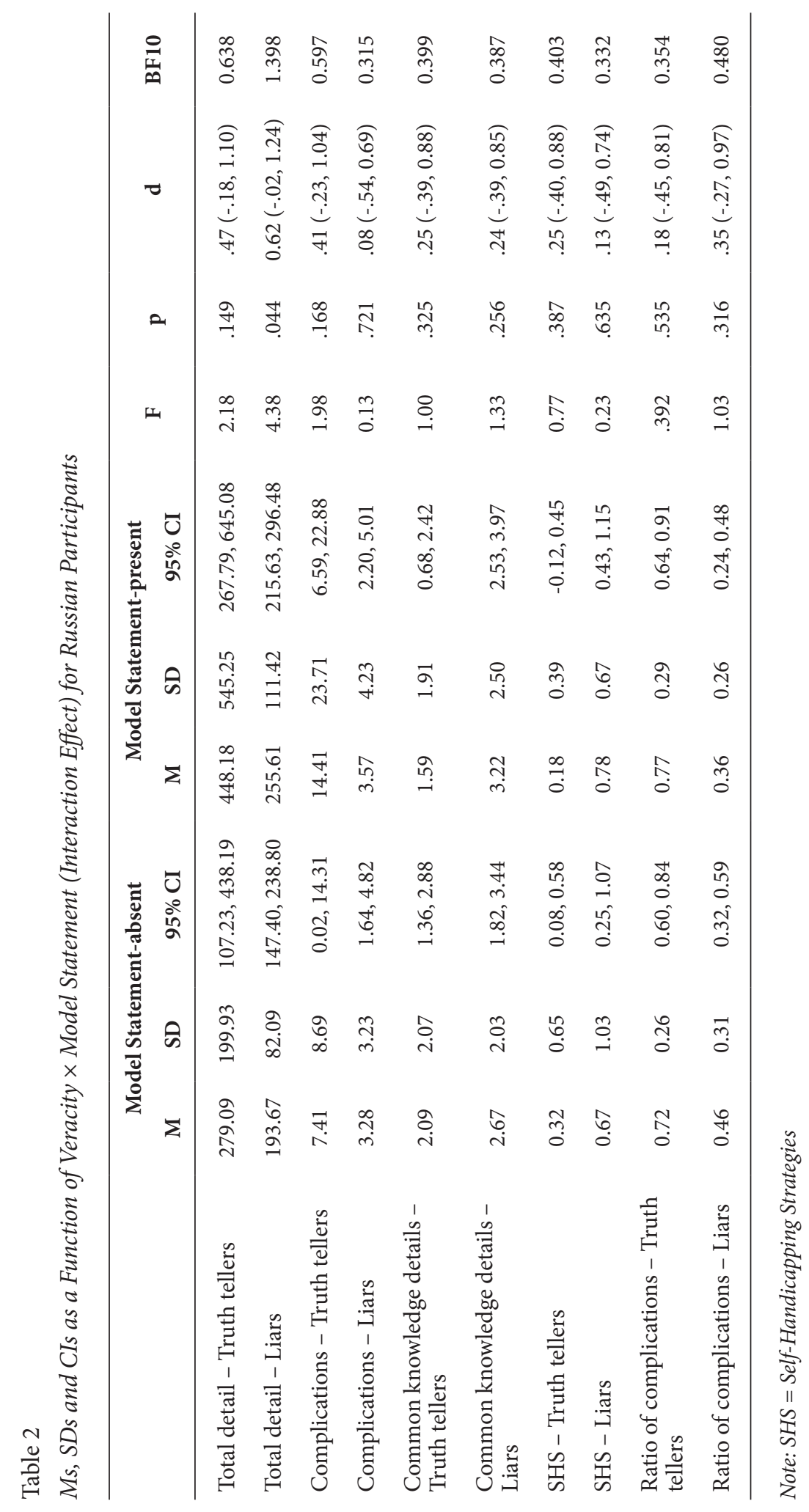


$p=.448, \eta_{\mathrm{p}}^{2}=.07$, and the Veracity $\times$ Model Statement effect were not significant, $F(5,69)=0.80, p=.552, \eta_{\mathrm{p}}{ }^{2}=.06$. The Veracity main effects are reported in Table 1. Truth tellers reported more complications and fewer common knowledge details than liars (weak effect according to $\mathrm{BF}_{10}$ ), supporting Hypothesis $2 \mathrm{a}$ and to some extent Hypothesis $2 \mathrm{~b}$. Also the ratio of complication score was higher for truth tellers than for liars. The difference for total details was marginally significant, with truth tellers reporting more details than liars (weak effect according to $\mathrm{BF}_{10}$ ), providing some support for Hypothesis 1. Ratio of complications was a more diagnostic cue than total details, supporting Hypothesis 3.

Even at a univariate level, none of the Model Statement effects were significant, although the effect for details reached borderline significance, $F(1,73)=3.36$, $p=.071, d=.34,95 \% \mathrm{CI}[.02, .64], \mathrm{BF}_{10}=0.62$. The BF results, however, provide support for the null hypothesis. Participants reported a similar number of details in the Model Statement-present $(M=337.45, S D=371.84,95 \%$ CI $[149.06,324.15])$ and in the Model Statement-absent condition $(M=240.65, S D=162.21,95 \%$ CI [262.81, 439.13]). Hypothesis 4 is thus rejected.

We present the Veracity $\times$ Model Statement interaction effect in Table 2 to provide the full set of results. Table 2 shows that the Model Statement had no effect on truth tellers in the Russian sample. None of the effects were significant and all $\mathrm{BF}_{10}$ scores $<1.00$. Liars reported more details in the Model Statement-present condition than in the Model Statement-absent condition, but the Bayes Factor indicates only weak evidence for this effect. The Bayes Factors further showed strong support for the null hypothesis for the non-significant effects in liars (all $\mathrm{BF}_{10}$ scores $\left.<1.00\right)$.

\section{Korean Participants}

A 2 (Veracity) $\times 2$ (Model Statement) MANCOVA was conducted with detail, complications, common knowledge details, self-handicapping strategies, and ratio of complications as dependent variables and preparation time, number of days discussed during the interview and interpreter as covariates. At a multivariate level, significant main effects emerged for Veracity, $F(5,69)=7.01, p<.001$, $\eta_{\mathrm{p}}{ }^{2}=.34$, and Model Statement, $F(5,69)=7.17, p<.001, \eta_{\mathrm{p}}{ }^{2}=.34$. The Veracity $\times$ Model Statement interaction effect was also significant, $F(5,69)=3.91, p=.004$, $\eta_{\mathrm{p}}^{2}=.22$.

Table 1 shows that truth tellers reported more details and more complications, but fewer common knowledge details than liars, supporting Hypotheses 1, 2a, and $2 b$. The ratio of complications score was also higher for truth tellers than for liars and this proportion score was a more diagnostic cue than total details. This supports Hypothesis 3.

Regarding the Model Statement main effects, participants in the Model Statement- present condition reported more details (supporting Hypothesis 4) and complications than participants in the Model Statement-absent condition (see Table 3). The ratio of complications score was also higher in the Model Statement-present condition than in the Model Statement-absent condition.

Truth tellers in the Model Statement-present condition, compared to truth tellers in the Model Statement-absent condition, reported more details, more compli- 


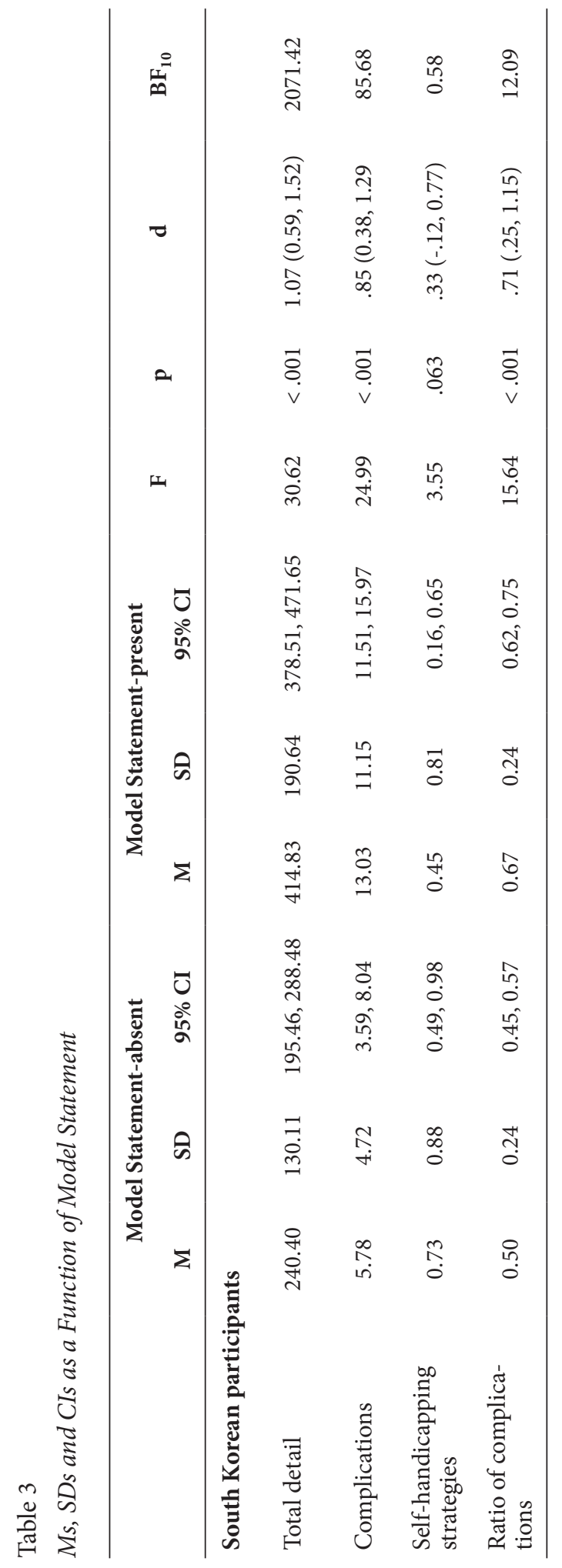




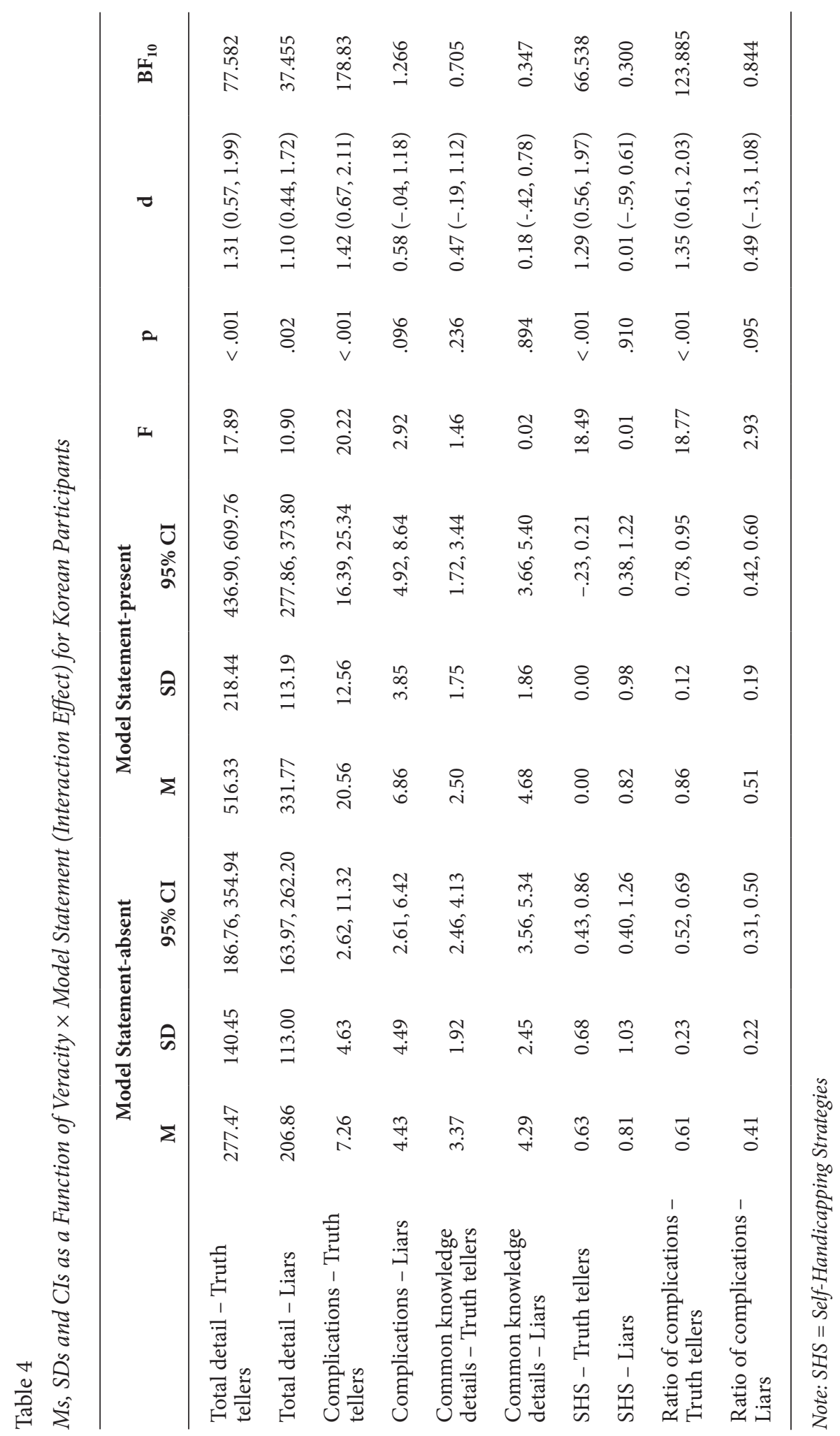


cations, and fewer self-handicapping strategies (see Table 4). Subsequently, they also obtained a higher ratio of complications score. Liars in the Model Statementpresent condition reported more details than did liars in the Model Statementabsent condition, but the other effects were not significant. The Bayes Factor analyses showed that all significant effects were substantial and that most non-significant effects supported the null hypothesis (the exception was liars' complications, which showed weak support in favour of the alternative hypothesis).

\section{Discriminant Analyses}

We tested the utility of the Model Statement for eliciting cues to deceit and focused on the three main dependent variables: total detail, complications, and ratio of complications. We ran discriminant analyses for the Model Statement-absent and Model Statement-present conditions separately and made a further distinction between Russian and Korean participants. In each case, the objective group to which the person belongs (truthful versus deceptive) was the classifying variable and the

Table 5

Results of the Discriminant Analyses

\begin{tabular}{|c|c|c|c|c|c|c|c|}
\hline & Truth \% & Lie \% & Total \% & $\mathrm{X} 2(1)$ & $\begin{array}{l}\text { Wilk's } \\
\text { Lambda }\end{array}$ & $\mathbf{p}$ & $\begin{array}{l}\text { Canonical } \\
\text { correlation }\end{array}$ \\
\hline \multicolumn{8}{|c|}{ Model Statement-absent Russian participants } \\
\hline Details & & & & 2.738 & .930 & .098 & .265 \\
\hline Complications & & & & 3.429 & .913 & .064 & .296 \\
\hline $\begin{array}{l}\text { Proportion of } \\
\text { complications }\end{array}$ & 63.6 & 61.1 & 62.5 & 7.661 & .815 & .006 & .430 \\
\hline \multicolumn{8}{|c|}{ Model Statement-present Russian participants } \\
\hline Details & & & & 2.610 & .933 & .106 & .259 \\
\hline Complications & 17.6 & 91.3 & 60.0 & 4.333 & .891 & .037 & .330 \\
\hline $\begin{array}{l}\text { Proportion of } \\
\text { complications }\end{array}$ & 76.5 & 78.3 & 77.5 & 16.973 & .636 & $<.001$ & 603 \\
\hline \multicolumn{8}{|c|}{ Model Statement-absent South Korean participants } \\
\hline Details & & & & 2.938 & 0.925 & .087 & .274 \\
\hline Complications & & & & 3.629 & 3.629 & .057 & .304 \\
\hline $\begin{array}{l}\text { Proportion of } \\
\text { complications }\end{array}$ & 68.4 & 76.2 & 72.5 & 6.998 & .830 & .008 & .413 \\
\hline \multicolumn{8}{|c|}{ Model Statement-present South Korean participants } \\
\hline Details & 50.0 & 77.3 & 65.0 & 10.188 & .762 & .001 & .488 \\
\hline Complications & 66.7 & 95.5 & 82.5 & 18.093 & .617 & $<.001$ & .619 \\
\hline $\begin{array}{l}\text { Proportion of } \\
\text { complications }\end{array}$ & 88.9 & 86.4 & 87.5 & 30.09 & .448 & $<.001$ & .743 \\
\hline
\end{tabular}


predictors were details, complications, or the ratio of complications or details. We report the "leave one out" classification results. All the relevant statistical information is provided in Table 5.

In the Russian sample, "complications" was a more diagnostic cue to deceit in the Model Statement-present than in the Model Statement-absent condition, supporting Hypothesis 5. In addition, the ratio of complications was the best indicator of deceit, particularly in the Model Statement-present condition, supporting Hypothesis 6 . The obtained accuracy rate in that condition was high $(77.5 \%)$ and shows a positive effect for using a Model Statement even for the Russian participants. For the Korean participants, truth tellers and liars could be correctly classified based on "complications" in the Model Statement-present condition, but not in the Model Statement-absent condition, supporting Hypothesis 5. In addition, the ratio of complications variable was a more diagnostic cue to deceit in the Model Statement-present condition than in the Model Statement-absent condition, supporting Hypothesis 6 . The obtained accuracy rate for ratio of complications in the Model Statement-present condition was particularly high, 87.5\%. The Model Statement had a stronger effect on South Korean than on Russian participants, supporting Hypothesis 8.

\section{Discussion}

As predicted, a Model Statement elicited more information (albeit in South Korean participants only), and strengthened complications and the ratio of complications as a cue to deceit in both Russian and South Korean participants. This means that the Model Statement technique has now been demonstrated to be effective in three cultures: British, Russian, and South Korean, suggesting that this technique can be used cross-culturally.

We predicted that the Model Statement technique would work better amongst South Korean than Russian participants and found evidence for it. However, we predicted this based on the expectation that South Koreans would provide fewer details than would Russians, which did not happen. This means that we can only speculate why the Model Statement technique was more effective in the South Korean than in the Russian sample. Perhaps the South Korean liars did not perform as well as the Russian liars because the South Korean liars may have travelled less than the Russian liars and thus had less experience to draw on. This would explain why the Russians reported more days away in their stories and also why they felt more than their South Korean counterparts did - that the preparation time was sufficient: If someone has done something many times, it is easier to think of how to lie about it than when someone has to completely make up an unusual event. This could also explain why the South Korean participants included more common knowledge details in their stories than did the Russian participants. The Russians may have embedded some truths from another trip (idiosyncratic details) in their lies, whereas the South Koreans may have been less able to do so. To test this speculation, the number of holidays/trips previously taken should be taken into account in future research. 


\section{Acknowledgements}

This work is funded by the High-Value Detainee Interrogation Group, DJF-151299-V-0010271, awarded to the University of Portsmouth (UK). Any opinions, findings, conclusions, or recommendations expressed in this article are those of the authors and do not necessarily reflect the views of the U.S. Government.

\section{References}

Amado, B. G., Arce, R., Fariña, F., \& Vilarino, M. (2016). Criteria-Based Content Analysis (CBCA) reality criteria in adults: A meta-analytic review. International Journal of Clinical and Health Psychology, 16, 201-210. https://doi.org/10.1016/j.ijchp.2016.01.002

DePaulo, B. M., Lindsay, J. L., Malone, B. E., Muhlenbruck, L., Charlton, K., \& Cooper, H. (2003). Cues to deception. Psychological Bulletin, 129, 74-118. https://doi.org/10.1037/0033-2909.129.1.74

Hall, E. T. (1976). Beyond culture. Garden City, N.Y.: Anchor Press. https://doi. org/10.1525/aa.1978.80.2.02a00330

Hartwig, M., Granhag, P. A., \& Strömwall, L. (2007). Guilty and innocent suspects'strategies during police interrogations. Psychology, Crime, \& Law, 13, 213-227. https://doi. org/10.1080/10683160600750264

Jeffreys, H. (1961). Theory of probability. Oxford, UK: Oxford University Press.

Lakens, D. (2016, January 14). Power analysis for default Bayesian $t$-tests [Blog post]. Retrieved from http://daniellakens.blogspot.com/2016/01/power-analysis-for-default-bayesian-t.html

Leal, S., Vrij, A., Warmelink, L., Vernham, Z., \& Fisher, R. (2015). You cannot hide your telephone lies: Providing a model statement as an aid to detect deception in insurance telephone calls. Legal and Criminological Psychology, 20, 129-146. https://doi.org/10.1111/lcrp.12017

Liu, M. (2016). Verbal communication styles and culture. In Oxford research encyclopedia of communication. Oxford, UK: Oxford University Press. https://doi. org/10.1093/acrefore/9780190228613.013.162

Ruby, C. L., \& Brigham, J. C. (1998). Can Criteria-Based Content Analysis distinguish between true and false statements of African-American speakers? Law and Human Behavior, 22, 369-388. https://doi.org/10.1023/A:1025766825429

Sporer, S. L. (2016). Deception and cognitive load: Expanding our horizon with a working memory model. Frontiers in Psychology: Hypothesis and Theory, 7, article 420. https://doi. org/10.3389/fpsyg.2016.00420

Vrij, A. (2008). Detecting lies and deceit: Pitfalls and opportunities, second edition. Chichester: John Wiley and Sons.

Vrij, A., \& Granhag, P. A. (2012). Eliciting cues to deception and truth: What matters are the questions asked. Journal of Applied Research in Memory and Cognition, 1, 110-117. https:// doi.org/10.1016/j.jarmac.2012.02.004

Vrij, A., Hope, L., \& Fisher, R. P. (2014). Eliciting reliable information in investigative interviews. Policy Insights from Behavioral and Brain Sciences, 1, 129-136. https://doi. org/10.1177/2372732214548592

Vrij, A., Leal, S., \& Fisher, R. P. (2018). Verbal deception and the Model Statement as a lie detection tool. Frontiers in Psychiatry, section Forensic Psychiatry, 9, 492. https://doi. org/10.3389/fpsyt.2018.00492

Vrij, A., Leal, S., Jupe, L., \& Harvey, A. (2018). Within-subjects verbal lie detection measures: A comparison between total detail and proportion of complications. Legal and Criminological Psychology, 23, 265-279. https://doi.org/10.1111/lcrp.12126 
Vrij, A., Leal, S., Mann, S., Dalton, G. Jo, E., Shaboltas, A., Khaleeva, M., Granskaya, J., \& Houston, K. (2017). Using the Model Statement to elicit information and cues to deceit in interpreterbased interviews. Acta Psychologica, 177, 44-53. https://doi.org/10.1016/j.actpsy.2017.04.011

Wetzels, R., \& Wagenmakers, E. J. (2012). A default Bayesian hypothesis test for correlations and partial correlations. Psychonomic Bulletin \& Review, 19, 1057-1064. https://doi. org/10.3758/s13423-012-0295-x

Original manuscript received January 30, 2019 Revised manuscript accepted April 15, 2019 First published online May 30, 2019

To cite this article: Vrij A., Leal, S., Mann, S., Shaboltas, A., Khaleeva, M., Granskaya, J., Jo, E. (2019). Using the Model Statement Technique as a Lie Detection Tool: A CrossCultural Comparison. Psychology in Russia: State of the Art, 12(2), 19-33. DOI: 10.11621/ pir.2019.0202 